(2) Open Access Full Text Article

\title{
Two-step surgery for retinal detachment caused by myopic macular hole
}

This article was published in the following Dove Press journal:

Clinical Ophthalmology

30 October 2012

Number of times this article has been viewed

\section{Joo Eun Lee}

Department of Ophthalmology, Inje University College of Medicine, Busan, South Korea
Correspondence: Joo Eun Lee

Department of Ophthalmology,

Haeundae Paik Hospital, Inje University

College of Medicine, 875 Haeundae-ro,

Busan 612-030, South Korea

$\mathrm{Tel}+82517972310$

Fax $+825 \mid 797232$ I

Email jooeun2@paik.ac.kr
Purpose: To report the results of a two-step operation for treating retinal detachments caused by macular holes in high-myopic patients.

Methods: In the first part of the operation, pars plana vitrectomy, air-fluid exchange, and silicone oil injection were performed. At 4-6 months after the first operation, the second part of the operation was performed. This involved silicone oil removal and internal limiting membrane peeling under the aid of triamcinolone acetonide with or without gas tamponade.

Results: Four eyes (four patients) underwent surgery with this technique. All retinas were attached at the time of the second operation, when internal limiting membrane peeling could be performed easily and safely. The retina remained attached in all four eyes (100\%) during 24-32 months of follow-up after the second operation.

Conclusion: Favorable surgical results were obtained with the two-step operation in the treatment of retinal detachments resulting from myopic macular holes.

Keywords: internal limiting membrane peeling, macular hole, macular hole retinal detachment, retinal detachment, silicone oil, two-step

\section{Introduction}

Macular buckling and vitrectomy are the two main methods used for treating myopic patients with retinal detachments caused by macular holes. ${ }^{1,2}$ In the case of vitrectomy, surgical results have improved since the internal limiting membrane (ILM) peeling technique became widely used. ${ }^{2}$ However, beginning retinal surgeons, and sometimes even experienced surgeons, find it challenging to peel the ILM on the detached retina. Subretinal migration of indocyanine green, which is commonly used to facilitate ILM peeling, and subsequent toxicity is another concern. ${ }^{3}$ To resolve this problem, the authors introduce a two-step operation involving vitrectomy and temporary silicone oil injection for the first part, and oil removal and ILM peeling for the second part.

\section{Patients and methods}

In this study, four consecutive patients who had been treated by a two-step surgery for myopic macular hole retinal detachments were followed for at least 2 years. Patients' data were retrospectively reviewed.

\section{Surgical technique}

First operation

A standard three-port pars plana vitrectomy was performed. After complete vitrectomy and posterior hyaloid separation were completed, air-fluid exchange and then silicone 
oil injection were performed. The patient was asked to maintain a facedown position for 2 weeks postoperatively.

\section{Second operation}

The second operation was performed 4-6 months after the first operation. First, phacoemulsification and posterior chamber intraocular lens insertion were performed in patients who had developed cataract after the first operation (patients 2, 3, and 4). Three standard pars plana sclerotomies were made, and silicone oil was removed using a 20-gauge soft cannula. After careful examination of the posterior and peripheral retina, ILM peeling was performed. Triamcinolone crystal was used to improve visualization of the ILM. Two to three disc diameters of ILM were removed around the macular hole in a continuous curvilinear fashion. Air-fluid exchange was performed in two patients (patients 3 and 4), and additional total gas exchange was completed with sulfur hexafluoride to achieve $20 \%$ concentration in one patient (patient 4) with an evident macular hole margin.

\section{Results}

Preoperative demographics and postoperative results are summarized in Table 1. All patients had myopia greater than 5 diopters (range: -5.0 to $-7.75 \mathrm{D}$ ). Axial length ranged from 25.1 to $29.9 \mathrm{~mm}$. All second operations were performed 4-6 months after the first operation. Retinal reattachment was achieved in all four patients, and no patient showed recurrence during 24-32 months of follow-up after the second operation (Figure 1). Postoperative vision improved in all patients.

\section{Discussion}

Macular holes are often accompanied by retinal detachment in high-myopic patients, and rarely in nonmyopic patients. The two main risk factors for retinal detachment include tangential traction ${ }^{4}$ and posterior staphyloma. ${ }^{1}$ To resolve these problems, various surgical techniques have been tried with variable success rates.

Some authors advocate the use of macular buckling to overcome the geometric imbalance between the neurosensory retina and the retinal pigment epithelium-choroid-sclera complex caused by posterior staphyloma. ${ }^{1}$ However, metamorphopsia due to distortion of the macular area and the difficulty of the technique have created concern as potential problems.

Various techniques involving vitrectomy have been used to reduce tangential traction around the macular hole, and these techniques have the potential to provide an anatomical

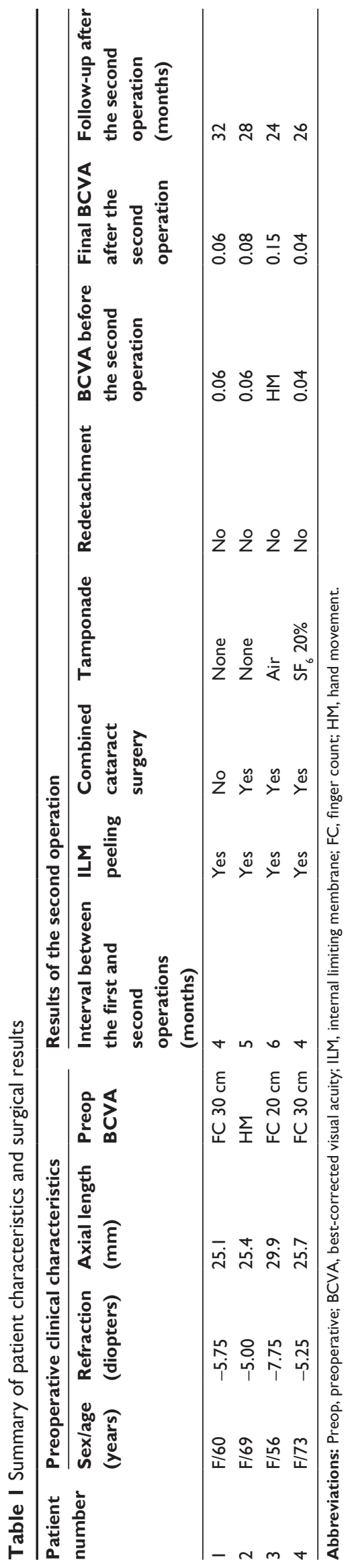




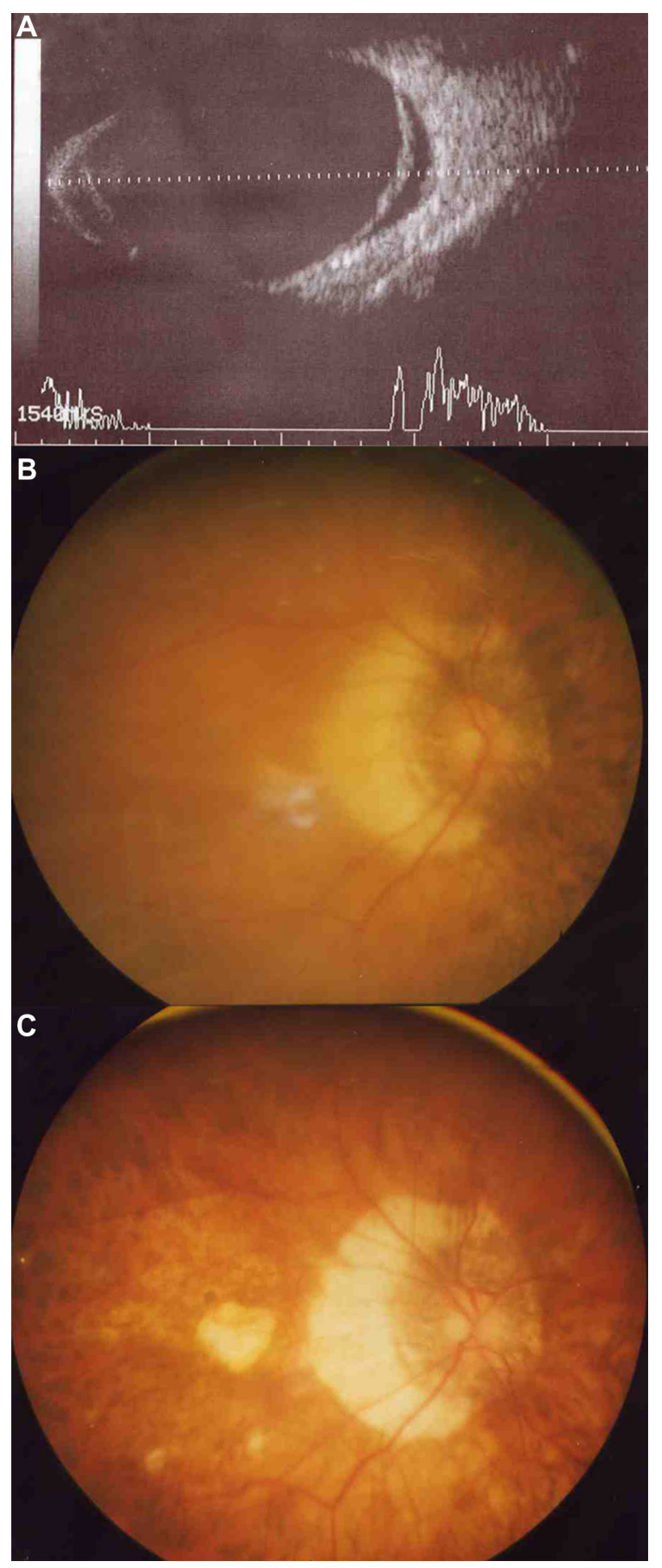

Figure I (A-C) Pictures of patient 3. Preoperative B-scan ultrasonography (A) shows that the detached retina is overhanging the posterior staphyloma. The retina of the posterior pole is detached preoperatively (B). After the second operation, the retina is completely reattached and shows appearance characteristic of high-myopic eye (C).

success rate as high as $92.3 \%$ when used in combination with ILM peeling. ${ }^{2,4}$ Enhanced retinal flexibility achieved by complete removal of the ILM and the overlying epiretinal membrane could counter the centrifugal force caused by posterior staphyloma. ${ }^{2}$ However, this procedure can be challenging even for experienced surgeons, because of fluctuations of the detached retina. This can be partly overcome by counterpressure through bimanual technique ${ }^{2}$ or the use of perfluorocarbon liquid; ${ }^{5}$ both of these methods can still be tricky for beginning retinal surgeons. Subretinal migration of indocyanine green through the macular hole is another concern, since this can cause retinal pigment epithelial toxicity. ${ }^{3}$

These two problems can be resolved by employing the two-step operation described here. Initial settling of a detached retina by vitrectomy and temporary silicone oil injection transforms the macular hole retinal detachment into a simple macular hole configuration, which most retinal surgeons are familiar with. ILM peeling can be performed successfully without any additional measures except for triamcinolone acetonide treatment to enhance visualization of the ILM. One disadvantage of this technique is that it requires two separate operations. However, it allows the surgeon to peel the ILM and epiretinal membrane more comfortably and completely, offering a higher success rate in this hard-to-treat type of retinal detachment.

The interval between the first and the second operation was determined arbitrarily. Several months in the current study may be too long to preserve the potential of the retina to improve in visual acuity. More experience will be required to determine the optimal timing for second operation.

Important limitations in our study were difficulty reaching a general conclusion due to a small number of patients. Since late recurrence and long axial length are traits common to retinal detachment due to a myopic macular hole, relatively short follow-up and short axial length of the patients may be other limitations. Also, there are still controversies over the effect of ILM peeling for retinal detachment due to a macular hole, and more importantly optical coherence tomography data regarding the macular hole status after the first surgery was not available.

Despite all these limitations, a quite favorable result was procured from this small pilot study. The results suggest that two-step approach to peel the ILM could be an option in treating retinal detachment due to a myopic macular hole, and would be helpful especially to beginning retinal surgeons who still are not comfortable peeling the ILM on a detached retina.

\section{Disclosure}

The author has no financial interest related to the article.

\section{References}

1. Ando F, Ohba N, Touura K, Hirose H. Anatomical and visual outcomes after episcleral macular buckling compared with those after pars plana vitrectomy for retinal detachment caused by macular hole in highly myopic eyes. Retina. 2007;27(1):37-44. 
2. Kadonosono K, Yazama F, Itoh N, et al. Treatment of retinal detachment resulting from myopic macular hole with internal limiting membrane removal. Am J Ophthalmol. 2001;131(2):203-207.

3. Lee JE, Yoon TJ, Oum BS, Lee JS, Choi HY. Toxicity of indocyanine green injected into the subretinal space: subretinal toxicity of indocyanine green. Retina. 2003;23(5):675-681.

4. Uemoto R, Yamamoto S, Tsukahara I, Takeuchi S. Efficacy of internal limiting membrane removal for retinal detachments resulting from a myopic macular hole. Retina. 2004;24(4):560-566.
5. Brazitikos PD, Androudi S, Dimitrakos SA, Stangos NT. Removal of the internal limiting membrane under perfluorocarbon liquid to treat macular-hole-associated retinal detachment. Am J Ophthalmol. 2003;135(6):894-896.

\section{Publish your work in this journal}

Clinical Ophthalmology is an international, peer-reviewed journal covering all subspecialties within ophthalmology. Key topics include: Optometry; Visual science; Pharmacology and drug therapy in eye diseases; Basic Sciences; Primary and Secondary eye care; Patient Safety and Quality of Care Improvements. This journal is indexed on

\section{Dovepress}

PubMed Central and CAS, and is the official journal of The Society of Clinical Ophthalmology (SCO). The manuscript management system is completely online and includes a very quick and fair peer-review system, which is all easy to use. Visit http://www.dovepress.com/ testimonials.php to read real quotes from published authors. 